\title{
Cocoa Pods and Seeds Characteristics of Different Hybrid Varieties in Southeastern Ghana
}

\author{
Daniel Ako Tetteh ${ }^{1}$, Daniel Obeng ${ }^{2}$ \\ ${ }^{1}$ Department of Environmental Health Education, University of Education, Winneba, Ghana \\ ${ }^{2}$ College of Ghana, Wisconsin International University, North-Legon, Ghana
}

\section{Email address:}

danieltet2003@yahoo.com (D. A. Tetteh)

\section{To cite this article:}

Daniel Ako Tetteh, Daniel Obeng. Cocoa Pods and Seeds Characteristics of Different Hybrid Varieties in Southeastern Ghana. Ecology and Evolutionary Biology. Vol. 6, No. 3, 2021, pp. 88-91. doi: 10.11648/j.eeb.20210603.13

Received: May 8, 2021; Accepted: June 1, 2021; Published: August 2, 2021

\begin{abstract}
The purpose of the study was to determine cocoa seed and pod characteristics of different cocoa hybrid varieties. We obtained the hybrid cocoa pods between the months of July and August, 2020 from Seed Production Division, of the Ghana Cocoa Board. We determined the characteristics of the cocoa pods and seeds using three clonal varieties namely $\mathrm{C} 67, \mathrm{C} 85$ and PA 150. The research method was a survey and descriptive method. The observed parameters were number of cocoa seeds per pod, pod diameter, pod length and fresh seed weight. We selected the cocoa pods, weighed and grouped into large size, medium size and small size cocoa pods. The number of seeds per pod was high in clone PA 150 in large cocoa pod size. Average fresh seed weight was high in clone 67 while length of pod of cocoa was high in medium cocoa pod size in clone 85 . Average pod diameter was high in clone PA 150. The relationship between the number of seeds per pod and pod length was significant and positively correlated. For a successful cocoa production, analysis of the physical characteristics of cocoa pod and seeds should be encouraged in order to provide useful information for future breeding strategies, on-farm selection and conservation efforts.
\end{abstract}

Keywords: Characteristics, Pod, Beans, Cocoa, Varieties

\section{Introduction}

Cocoa is one of the most important agricultural export commodities in the world and forms the backbone of the economies of some countries in West Africa, such as Coted'Ivoire, Ghana, Nigeria and Cameroon $[1,6,10]$. The economic value of cocoa is determined by the quality of the beans which include flavor, fat content, average seed weight, skin content, moisture content and defective seeds [7, 12]. However, despite the economic benefits derived from the cocoa beans by contributing to GDP and providing livelihood to millions of people within the cocoa value chain, preliminary study indicates that data on cocoa pod size and seeds characteristics in Ghana and within the humid tropics is lacking.

Cocoa seeds commonly known as cocoa beans are obtained from the pods. These pods are oval in shape, measure between 12 and $30 \mathrm{~cm}$ long, and contain 30 to 40 beans embedded in a mucilaginous pulp, which comprises approximately $40 \%$ of the bean fresh weight [8]. According to Sosu [9], the seed number and size are essential factors for determining cocoa yield. The pod has been described as a natural laminated material consisting of three distinctly different layers: epicarp, mesocarp and endocarp (outer, middle and inner pericarp, respectively. Cocoa pods vary in colour from green to red or purple and thickness when ripe depending on their clone. The seeds are the main ingredients of chocolate, while the pulp is used in some countries to prepare refreshing juice, smoothies and jelly. Each seeds contains significant amount of fat (40 to 50\%) as cocoa butter [5].

In most parts of the world, cocoa farmers prefer extracting seeds from a selected number of pods after harvest or purchase seedlings raised from recognized seed producers or dealers. A recent study conducted by [11], revealed that most cocoa farmers in Ghana are faced with challenges in choosing the right cocoa pod size that will give a higher yield. This is because farmers cannot see the content of the pods of cultivars which they are selecting for seed extraction. Farmers generally have the perception that the size and weight of the cocoa pod is 
directly proportional to the number and size of seeds found within the pod [12]. Establishing scientific evidence by way of the outcome of this study on the relationship between the size of the cocoa pod and its parameters would contribute immensely in providing information on a potentially less costly alternative for farmers towards improving and increasing cocoa yield. This information is important in making strategic management plans for future breeding programs, on-farm selection for high cocoa yields and conservation efforts. The purpose of the study was to determine cocoa seed and pod characteristics. Specifically, the study was designed to address the following questions: (1) does the size of the cocoa pod affect the numbers of seeds? (2) Is there a relationship between the number of cocoa seeds, pod length and pod diameter of the hybrid cocoa varieties under investigation?

\section{Materials and Methods}

\subsection{Study Area}

The study was carried out in Suhum-Municipality located in the South-Central part of the Eastern Region of Ghana and covers a land area of about $400 \mathrm{~km}^{2}$. Geologically, Suhum is situated between latitude $00^{\circ} 56^{\prime} \mathrm{N}$ and latitude $60^{\circ} 081^{\prime} \mathrm{N}$ and longitude $00^{\circ} 33^{\prime} \mathrm{W}$ and Longitude $00^{\circ} 161^{\prime}$ $\mathrm{W}$ [4]. Mean annual rainfall of the area is between 1270 $\mathrm{mm}$ and $1651 \mathrm{~mm}$ with the major raining season occurring between the months of April and July while the minor season falls between the months September and November [5]. Mean monthly temperature in the area is between $24^{\circ} \mathrm{C}$ and $29^{\circ} \mathrm{C}$. Ecologically, Suhum lies within the semideciduous forest zone but anthropogenic activities such as agriculture, logging and extraction of fuelwood have reduced the original vegetation to an insignificant level and the land is now mainly covered by fallows and secondary forest. The shaded-cocoa systems in the area are mostly mixed stands of cocoa with variable proportions of naturally generated upper canopy shade trees such as Terminalia superba Engl. \& Diels, Entandophragma angolense (Welw.) C. DC, Alstonia boonei de Wild, Antiaris toxicaria Lesch. and Spathodea campanulata P. Beauv. Increasingly, fruit trees including orange (Citrus sinensis) (L.) Osbeck, Avocado (Persea americana Mill.) and mango (Mangifera indica L.) are planted for shade, food and other purpose.

\subsection{Methods}

We obtained hybrid cocoa pods from the Ghana Cocoa Board, Seed Production Division, Bunso, between the months of July and August, 2019. We purposively selected the cocoa pods, weighed and grouped into large size, medium size and small size cocoa pods. A total of two hundred and ninety seven (297) ripe cocoa comprising of ninety nine pods each of three hybrids (Hybrid C67, Hybrid C85 and Hybrid PA 150) were obtained for the study. The average weights of the various hybrid cocoa pods were determined using an electronic balance after grouping the pods into treatments that is small, medium and large. The fresh seeds were dried to the required moisture content following Ghana Cocoa Board protocol for drying cocoa beans. The number of seeds per treatment was counted. Pod length was determined by measuring the distance between the points of attachment to the pod to the apex of the pod using a tape measure. The circumference of the pod was measured using a vernier caliper along the widest section of the pod after which the diameter of the pods was computed by dividing the circumference by pi.

\subsection{Statistical Analysis}

We analyzed the data using one-way analysis of variance (ANOVA) to explore significant differences in the means of the number of seeds per pod, fresh seed weight, length of pod and pod diameter after the assumption of normality was tested using Shapiro-Wilk statistic tests. Spearman's coefficient of correlation was conducted to determine the relationships between the number seeds per pod, length of pod and pod diameter of the different cocoa hybrid varieties. The data was analyzed using R software version 3.1.1 [3].

\section{Results}

\subsection{Characteristics of Cocoa Seeds and Pods}

Mean number of cocoa seeds per pod was significantly related to the different treatments $(\mathrm{p}<0.001)$. Large cocoa pod size contained the largest $(38.93 \pm 2.25)$ average seeds per pod with small pod size recording the lowest $(31.24 \pm 1.59)$ in clone 67 . The difference observed in the number seeds per pod was between small cocoa pod size and medium cocoa pod size (post hoc Tukey HSD, $\mathrm{p}=0.615$ ). For clone 85 , the number of seeds per pod was highest $(38.89 \pm 2.25)$ in large cocoa pod size and lowest $(28.17 \pm 0.09)$ in small cocoa pod size (Table 1).

Table 1. Physical parameters of cocoa seeds and pods of the different cocoa hybrid varieties.

\begin{tabular}{lllll}
\hline Parameters & Large size & Medium size & Small size & Statistical method of comparison of means post hoc pair wise comparisons) \\
\hline Hybrid C67 & & & & \\
Number of seeds per pod & $38.93 \pm 2.25$ & $33.36 \pm 2.25$ & $31.24 \pm 1.59$ & ANOVA, $\mathrm{p}<0.001$ \\
Fresh seed weight (g) & $78.52 \pm 4.45$ & $73.69 \pm 4.45$ & $44.85 \pm 3.15$ & ANOVA, $\mathrm{p}<0.001$ \\
Length of pod & $17.52 \pm 0.47$ & $18.98 \pm 0.47$ & $17.13 \pm 0.33$ & ANOVA, $\mathrm{p}<0.001$ \\
Pod diameter & $7.52 \pm 0.15$ & $8.09 \pm 0.21$ & $7.79 \pm 0.21$ & ANOVA, $\mathrm{p}<0.05$ \\
Hybrid C85 & & & & \\
Number of seeds per pod & $38.89 \pm 1.28$ & $34.03 \pm 1.28$ & $28.17 \pm 0.90$ & ANOVA, $\mathrm{p}<0.001$ \\
Fresh seed weight $(\mathrm{g})$ & $78.82 \pm 2.61$ & $75.34 \pm 2.61$ & $51.79 \pm 1.85$ & ANOVA, $\mathrm{p}<0.001$ \\
Length of pod & $19.49 \pm 0.33$ & $17.96 \pm 0.33$ & $17.87 \pm 0.22$ & ANOVA, $\mathrm{p}<0.001$ \\
\hline
\end{tabular}




\begin{tabular}{lllll}
\hline Parameters & Large size & Medium size & Small size & Statistical method of comparison of means post hoc pair wise comparisons) \\
\hline $\begin{array}{llll}\text { Pod diameter } \\
\text { Hybrid PA 150 }\end{array}$ & $7.49 \pm 0.18$ & $7.19 \pm 0.18$ & $6.97 \pm 0.13$ & ANOVA, $\mathrm{p}<0.05$ \\
Number of seeds per pod & $39.64 \pm 2.21$ & $34.93 \pm 2.21$ & $26.27 \pm 1.56$ & ANOVA, $\mathrm{p}<0.001$ \\
Fresh seed weight (g) & $72.94 \pm 4.26$ & $74.64 \pm 4.26$ & $50.15 \pm 0.30$ & ANOVA, $\mathrm{p}<0.001$ \\
Length of pod & $21.74 \pm 0.49$ & $19.48 \pm 0.49$ & $16.68 \pm 0.34$ & ANOVA, $\mathrm{p}<0.001$ \\
Pod diameter & $8.84 \pm 0.14$ & $7.96 \pm 0.14$ & $7.39 \pm 0.10$ & ANOVA, $\mathrm{p}<0.001$ \\
\hline
\end{tabular}

The fresh seed weight of cocoa seeds was significantly different $(\mathrm{p}<0.001)$ among the different pod sizes with the highest $(78.52 \pm 4.45 \mathrm{~g})$ recorded in large cocoa pod size while the lowest $(44.85 \pm 3.15 \mathrm{~g})$ was observed in small pod size in clone 67. The difference in fresh seed weight between the medium and large cocoa pod size was not significant (post hoc Tukey HSD, $\mathrm{p}=0.527$ ). Mean fresh weight was highest $(74.64 \pm 4.26 \mathrm{~g})$ in medium cocoa pod size and lowest $(50.15 \pm 0.30 \mathrm{~g})$ in small cocoa pod size for clone PA 150 . The weight of the fresh cocoa seeds varied significantly among the different treatments $(p<0.001)$. There was however, no significant difference observed between the medium and large cocoa pod sizes (post hoc Tukey, $\mathrm{P}=0.916$ ).

The mean length of cocoa pod showed significant difference among the different treatments $(\mathrm{p}<0.001)$. Mean length of cocoa pod was highest (18.89 \pm 0.47$)$ in medium cocoa pod size and lowest $(17.13 \pm 0.33)$ in small cocoa pod size for clone 67 . For clone 85 , the highest $(19.49 \pm 0.32)$ mean length of pod was recorded in large cocoa pod size and lowest $(17.87 \pm 0.22)$ was observed in small cocoa pod size. The length of pod showed significant difference among the different cocoa pod sizes $(\mathrm{p}<0.001)$. There was significant difference (Tukey HSD, $p<0.001$ ) in the mean pod length between the medium and large cocoa pod size and small and large cocoa pod size (Tukey HSD, $p<0.001$ ). There was however, no significant difference (Tukey HSD, $p=0.948$ ) between small and medium cocoa pod size. Mean pod length was significantly different among the different pod size for clone PA $150(\mathrm{p}<0.001)$. Large cocoa pod size recorded the highest $(21.74 \pm 0.49)$ mean pod length while the lowest $(16.68 \pm 0.34)$ was observed in small cocoa pod size.

The mean pod diameter of cocoa pod was highest $(8.09 \pm 0.21)$ in medium cocoa pod size and lowest (7.52 \pm 0.15$)$ in large cocoa pod size for clone 67 . Mean pod diameter differ significantly among the different treatments $(p<0.05)$. For clone 85 , significant difference was recorded in the mean pod diameter among the various treatments $(\mathrm{p}<0.05)$. Mean pod diameter was highest $(7.49 \pm 0.18)$ in large cocoa pod size and lowest $(6.97 \pm 0.13)$ in small cocoa pod size. The difference observed in pod diameter was between small cocoa pod size and large cocoa pod size (post hoc Tukey HSD, $\mathrm{p}=0.194$ ). Mean pod diameter varied significantly across the different treatments in clone PA $150(\mathrm{p}<0.001)$. The highest $(8.84 \pm 0.14)$ mean cocoa pod diameter was found in large cocoa pod size while small cocoa pod size recorded the lowest $(7.39 \pm 0.12)$.

\subsection{Relationship Between the Number of Seeds Per Pod, Pod Length and Pod Diameter}

With regard to the results of correlation analysis between the number of seeds per pod and length of cocoa pod across the different treatments, significant relationship were detected between the number of seeds per pod and length of pods in clone $85(\mathrm{r}=0.32, \mathrm{p}<0.001)$. The relationship between the number of seeds per pod and pod diameter was positively correlated $(\mathrm{r}=0.32, \mathrm{p}<0.001)$ (Table 2$)$. Results of the correlation analysis between the number of seeds and pod length across the different treatments in clone PA 150 showed significant positive relationship were observed $(\mathrm{r}=0.49, \mathrm{p}<$ 0.001 ). The number of seeds per pod and pod diameter was significant and positively correlated $(\mathrm{r}=0.31, \mathrm{p}<0.001)$. The association between the number of seeds and length of pod in clone 67 was negative and not significantly correlated $(\mathrm{r}=-0.42, \mathrm{p}>0.05)$. Number of seeds per pod was negatively related to the pod diameter across the different treatments $(r=-0.19, p<0.05)($ Table 2$)$.

Table 2. Relationship between number of seeds per pod, pod length and pod diameter of the different cocoa hybrid varieties.

\begin{tabular}{llll}
\hline \multirow{2}{*}{ Parameters } & Number of seeds per pod & \\
\cline { 2 - 4 } & Hybrid C67 & Hybrid C85 & Hybrid PA 150 \\
\hline Pod Length & $-0.04(\mathrm{p}=0.681)$ & $0.32^{* *}(\mathrm{p}=0.001)$ & $0.49^{* *}(\mathrm{p}=0.001)$ \\
Pod Diameter & $-0.19^{*}(\mathrm{p}=0.05)$ & $0.31^{* *}(\mathrm{p}=0.001)$ & $0.32^{* *}(\mathrm{p}=0.001)$ \\
\hline
\end{tabular}

\section{Discussion}

\subsection{Characteristics of Cocoa Seeds and Pods}

Average number of cocoa seeds per pod in this study was in consistent with values reported by the studies of (Tetteh \& Obeng, 2020) in Ghana and elsewhere [7]. The increase in number of seeds per pod could be attributed to the physiological development of the pods. The number of seeds per pod has been found to be an important trait for tracing variations in the morphological features of cocoa and also a determinant factor in measuring crop yield [1]. Clone PA 150 was observed to have recorded the highest number of cocoa seeds per pod in this study compared to the other cocoa hybrid varieties. Average fresh seed weight was high in large cocoa pod size in all the selected hybrid varieties due to the pod size and its physiological development. This assertion is contrary to values reported by Tetteh \& Obeng [11] in a similar study. Sitohang \& Siahaan [7], in a previous study observed length of cocoa pod similar to values reported in this study. However, variations existed in the length of pod of cocoa among the 
different hybrid varieties with large cocoa pod recording the highest pod length. This assertion agrees with study by Tetteh \& Obeng [11] who observed hybrid cocoa varieties with large pod size with a significant increase in pod length. It was observed from the study that PA 150 recorded the highest length of pods due to its genetic make-up compared to other cocoa hybrid varieties. Pod diameter in the different hybrid varieties varied among the large, medium and small cocoa pod sizes. Average pod diameter of cocoa pod in this study was similar to values reported by Sitohang \& Siahaan [7]. For clone 67 , pod diameter was high in medium pod size compared to large and small pod size. However, the situation was different in clone PA 150 and clone 85 .

\subsection{Relationship Between the Number of Seeds Per Pod, Pod Length and Pod Diameter}

In the determination of the characteristics of cocoa seeds and pods a close relationship might exist. In this study we found a significant positive relationship between the number seeds per pod and pod length of the various hybrid varieties which explains this relationship. Sitohang \& Siahaan [7], in a previous study reported a positive correlation with the length of pods and number seeds per pod variables similar to this study. The number of seeds per pod and pod diameter was reported to be positively correlated among the different hybrid varieties. The significant negative association between the number of seed per pods and pod length suggesting that pod length is not a determinant factor for predicting for number of seeds per pods.

\section{Conclusion}

In conclusion, the number of seeds per pod was high in clone PA 150 in large cocoa pod size. Average fresh seed weight was high in clone 67 while length of pod of cocoa was high in medium cocoa pod size in clone 85 . Average pod diameter was high in clone PA 150 . The relationship between the number of seeds per pod and pod length was significant and positively correlated.

\section{Acknowledgements}

I wish to express our profound gratitude to the director and staff of Seed Production Unit of the Ghana Cocoa Board for their assistance during the data collection.

\section{References}

[1] Aikpokpodion P. E., 2010. Variation in agro-morphological characteristics of cacao in farmers' fields in Nigeria. New Zealand Journal of Crop and Horticultural Science, 157-170.

[2] Abubarkar S., 2018. Determination of Physical characteristics of cocoa pods and seeds. Unpublished Diploma thesis

[3] Crawley M. J., 2007. The R book. Wiley, New York. Pp 942

[4] Ghana Statistical Service. 2010. Analysis of incentives and disincentives for cocoa in Ghana.

[5] Ghana Statistical Service (GSS). 2010 Population and Housing Census, summary report of final results. Accra, Ghana: Ghana Statistical Service.

[6] Nkamleu G. B., Nyemeck J, Gockowski J., 2010. Technology Gap and Efficiency in Cocoa Production in West and Central Africa: Implications for Cocoa Sector Development, Working Papers Series $\mathrm{N}^{\circ}$ 104, African Development Bank, Tunis, Tunisia.

[7] Sitohang N, and Siahaan R., 2018. Fruit Characteristics of Cocoa in Various Altitude Place. International Conference on Agribussines, Food and Agro-Technology.

[8] Schwan R. F., Wheals A. E., 2004. The microbiology of cocoa fermentation and its role in chocolate quality. Critical Reviews in Food Science and Nutrition, 44, 205-221.

[9] Sosu G., 2014. Growth of cocoa seedlings as affected by different growth media and different polybag sizes. Unpublished Master's thesis.

[10] Tetteh D. A., Asase A., 2017. Socioeconomic profile and farm management practices of smallholder cocoa farmers in three cocoa producing districts in Southwestern Ghana. African Journal of Agricultural Research.

[11] Tetteh D. A., and Obeng D., 2020. Analysis of cocoa seeds and pods in the Eastern region of Ghana. Unpublished MSc thesis

[12] Wardojo S., 1991. Some Basic Requirements for Improving the Quality of Indonesian Cocoa Beans. Proceedings of Cocoa III National Conference, Medan Plantation Research Center Jember Plantation Research Center - Indonesian Cocoa Association, ISBN 979-8168-01-1, Medan 7-9 March 1991, p. 75-85. 